\title{
Porphyromonas gingivalis Antigens and Interleukin- 6 Stimulate the Production of Monocyte Chemoattractant Protein-1 via the Upregulation of Early Growth Response-1 Transcription in Human Coronary Artery Endothelial Cells
}

\author{
Tomoki Maekawa ${ }^{a, b}$ Naoki Takahashia, ${ }^{a}$ Tomoyuki Honda ${ }^{a, b} \quad$ Daisuke Yonezawa ${ }^{a, b}$ \\ Hirotaka Miyashita a, b Takafumi Okuia,b Koichi Tabeta ${ }^{a}$ Kazuhisa Yamazakia, b \\ ${ }^{a}$ Center for Transdisciplinary Research, Niigata University, and ${ }^{b}$ Laboratory of Periodontology and Immunology, \\ Department of Oral Health and Welfare, Niigata University Faculty of Dentistry, Niigata, Japan
}

\section{Key Words}

Egr-1 $\cdot$ MCP-1 $\cdot$ Periodontitis $\cdot$ Atherosclerosis $\cdot$ Endothelial cell

\begin{abstract}
Background: Individuals with periodontitis have elevated serum levels of IL- 6 and C-reactive protein and have been reported to have a significantly increased risk of developing cardiovascular disease. The transcription factor early growth response factor 1 (Egr-1) has been shown to play an important role in the development and progression of atherosclerosis. However, it is not known whether periodontal infection affects the expression of Egr-1 and subsequent endothelial cells expression of monocyte chemoattractant protein (MCP)-1, a key molecule of leukocyte chemoattraction into vessels. Methods: Human coronary artery endothelial cells (HCAECs) were stimulated with either sonicated extracts from Porphyromonas gingivalis strains 381 or SU63, or a combination of IL- 6 and soluble IL- 6 receptor (IL-6/sIL-6R). The expression of Egr-1, and subsequently MCP-1, was then analyzed. The role of Egr-1 on MCP-1 expression was analyzed by siRNA transfection. Results: Both $P$. gingivalis anti-
\end{abstract}

gens and IL-6/sIL-6R stimulations upregulated the expression of Egr-1, with a more robust effect by IL-6/sIL-6R. Increased expression of Egr-1 coincided with MCP-1 production, and Egr-1 downregulation by siRNA suppressed this effect. Conclusion: These results clearly suggest that periodontal infection has the potential to affect HCAECs and hence contribute to the development of subsequent atherosclerosis.

Copyright $\odot 2009$ S. Karger AG, Basel

\section{Introduction}

Cardiovascular disease is currently the leading cause of death and illness in developed countries. Atherosclerosis is a progressive cardiovascular disease characterized by the accumulation of lipid and fibrous elements in the large arteries. A substantial body of evidence has implicated inflammation and immune activation in the pathogenesis of atherosclerosis [1]. Although the triggers that initiate and sustain the inflammatory process have not been conclusively determined, a number of potential triggers capable of inducing a pro-inflammatory response in endothelial cells have been identified; these include cy-

\section{KARGER}

Fax +4161306 1234 E-Mail karger@karger.ch www.karger.com
(C) 2009 S. Karger AG, Basel

$1018-1172 / 10 / 0474-0346 \$ 26.00 / 0$

Accessible online at:

www.karger.com/jvr
Prof. Kazuhisa Yamazaki

Periodontology and Immunology, Department of Oral Health and Welfare

Faculty of Dentistry, Niigata University

5274 Gakkocho 2-ban-cho, Niigata 951-8514 (Japan)

Tel./Fax +81 25227 0744, E-Mail kaz@ dent.niigata-u.ac.jp 
tokines and chemokines, in addition to classical risk factors such as modified lipoproteins, hypertension, hyperglycemia and smoking [2]. However, recent studies suggest that certain chronic infections also increase the risk of cardiovascular disease, either through a direct pro-inflammatory effect on the vessel wall, or through a less specific, prolonged pro-inflammatory effect $[1,3,4]$.

Periodontal disease is a chronic infection of the periodontium with a high prevalence in the general population, and is mainly associated with Gram-negative bacteria. Evidence supporting a link between periodontal disease and cardiovascular disease is accumulating in the literature. Data derived from a meta-analysis of 5 prospective cohort studies, 5 case-control studies and 5 cross-sectional studies suggested a positive correlation between periodontal disease and coronary heart disease (CHD) [5]. Although the mechanisms underlying this association are not clearly understood, it is reported that Aggregatibacter actinomycetemcomtans and Porphyromonas gingivalis, two representative periodontopathic bacteria, are detected in human atherosclerotic plaque as well as the oral cavity $[6,7]$. Characteristics of $P$. gingivalis are particularly implicated in the pathogenesis of atherosclerosis [8]. Our previous study demonstrated that a high frequency of antibody positivity for $P$. gingivalis SU63 but not for strain 381 was observed in patients with CHD. This suggests that this strain of $P$. gingivalis is probably involved in the mechanism linking periodontitis and CHD [9]. In addition, the degree of inflammation in periodontal disease is clearly sufficient to cause a systemic inflammatory response, as evidenced by an increase in C-reactive protein and IL- 6 in the serum of periodontitis patients compared with periodontally healthy subjects $[10,11]$.

Early growth response factor 1 (Egr-1) is an immediate-early gene that is rapidly and transiently induced by many stimuli, including hypoxia, shear stress and injury, and has emerged as a key regulator in the development of atherosclerosis. As a zinc finger nuclear protein, Egr-1 regulates a set of genes implicated in the pathogenesis of atherosclerosis, with subsequent thrombosis and restenosis, by acting as a master transcription factor $[12,13]$. The products of this set of genes include pro-inflammatory cytokines, chemokines, adhesion molecules, growth factors, coagulation factors and matricellular modulators.

Given that there is a suggested link between periodontal disease and cardiovascular disease, it is speculated that periodontal infection and/or resulting low-grade systemic inflammation could affect Egr-1 expression and subsequent cellular events. Here we demonstrate that $P$. gingivalis antigen upregulates Egr-1 expression and the subsequent production of monocyte chemoattractant protein (MCP)-1 in human coronary arterial endothelial cells. This effect is even more prominent with the combined stimulation of IL- 6 and soluble IL- 6 receptor (sIL$6 \mathrm{R})$, another mediator involved in periodontitis.

\section{Materials and Methods}

\section{Reagents and Antibodies}

Rabbit anti-human Egr-1 (Santa Cruz Biotechnology, Temecula, Calif., USA) and mouse anti-human GAPDH (Abcam, Cambridge, UK), along with the ECL Plus Western Blotting Reagent Pack (Amersham Biosciences, Little Chalfont, UK) were used for Western blotting. The primers and probe for real-time PCR for GAPDH were purchased from Applied Biosystems (Foster, Calif., USA). Recombinant human IL-6 (rhIL-6) and sIL-6R were purchased from R\&D Systems (Minneapolis, Minn., USA).

\section{Bacterial Strains and Culture}

P. gingivalis strain 381 and SU63 were cultured in modified Gifu anaerobic medium GAM broth (Nissui, Tokyo, Japan) in an anaerobic jar (Becton Dickinson Microbiology System, Cockeysville, Md., USA) in the presence of AnaeroPack ${ }^{\mathrm{TM}}$ (Mitsubishi Gas Chemical Co. Inc., Tokyo, Japan) for $48 \mathrm{~h}$ at $37^{\circ} \mathrm{C}$. Bacterial suspensions were prepared in phosphate-buffered saline (PBS) without $\mathrm{Mg}^{2+} / \mathrm{Ca}^{2+}$ using established growth curves and spectrophotometric analysis.

Preparation of $\mathrm{P}$. gingivalis Antigen

Freeze-dried bacteria were suspended in ice-cold PBS and micro glass beads (Glasperlen; Sartorius Mechatronics Japan, Tokyo, Japan) were added to the suspension at a concentration of 0.25 $\mathrm{g} / 10 \mathrm{ml}$. The suspension was treated with ultrasonic disruptor (Tomy Seiko Co. Ltd., Tokyo, Japan) for $3 \mathrm{~min}$ and repeated 5 times. The beads and debris were removed by centrifugation and the supernatant was ultracentrifuged at $100,000 \mathrm{~g}$ for $60 \mathrm{~min}$. The resultant supernatant was dialyzed against PBS and used as the antigens.

\section{Cell Culture}

Cryopreserved human coronary artery endothelial cells (HCAECs) were purchased from Cambrex Bio Science (Walkersville, Md., USA). The cells were grown in EBM-2 supplemented with EGM-2MV. The growth medium was changed every other day until confluence. The cells were used at passages 6-8. For stimulation, the cells were cultured in the growth medium at a concentration of $5 \times 10^{5}$ cells/well in a 12-well culture plate (TPPUS, St. Louis, Mo., USA) in a humidified atmosphere of $5 \% \mathrm{CO}_{2}$ and air at $37^{\circ} \mathrm{C}$ until subconfluence. After washing with Hanks' balanced salt solution 3 times, and preincubation with EBM-2 (Cambrex Bio Science) for $12 \mathrm{~h}$, P. gingivalis antigens (1 and 10 $\mu \mathrm{g} / \mathrm{ml}$ ) and various doses of rhIL- 6 and sIL-6R (IL-6: 0.1, 1.0, 10.0 $\mathrm{ng} / \mathrm{ml}$; sIL-6R: 0, 10.0, $100.0 \mathrm{ng} / \mathrm{ml}$ ) in EBM-2 supplemented with $10 \%$ fetal calf serum were added to the culture and stimulated for 1 or $16 \mathrm{~h}$ for gene expression analysis and protein assay, respectively, based on the results of preliminary experiments. 
Gene Expression Analysis

Total RNA was isolated from various types of unstimulated cells, and stimulated HCAECs using TRIZOL (Invitrogen, Carlsbad, Calif., USA) according to the manufacturer's instructions, and then treated with RNase-free DNase I (Invitrogen). The RNA was then reverse-transcribed to cDNA using a random primer (Takara Bio Inc., Shiga, Japan) and M-MLV reverse transcriptase (Invitrogen).

For real-time PCR, the primers and probes specific for Egr-1, MCP-1 and GAPDH were all purchased from Applied Biosystems. Reactions were conducted in a $25-\mu l$ reaction mixture in the ABI PRISM 7900HT Sequence Detection System (Applied Biosystems) by using TaqMan Gene Expression Assays (Applied Biosystems) containing $900 \mathrm{nM}$ primer and $250 \mathrm{nM}$ probe, and incubated for $10 \mathrm{~min}$ at $95^{\circ} \mathrm{C}$, followed by 40 cycles of a two-step amplification procedure composed of annealing/extension at $60^{\circ} \mathrm{C}$ for $1 \mathrm{~min}$ and denaturation for $15 \mathrm{~s}$ at $95^{\circ} \mathrm{C}$. ABI PRISM SDS 2.0 software (Applied Biosystems) was used to analyze the standards and to carry out the quantifications. The relative quantity of each mRNA was normalized to the relative quantity of GAPDH mRNA.

\section{Western Blotting}

The cultured cells were washed with ice-cold PBS twice and the protein was extracted using M-PER Mammalian Protein Extraction Reagent supplemented with a Halt Protease Inhibitor Cocktail Kit and Halt Phosphatase Inhibitor Cocktail (all from Pierce Biotechnology, Rockford, Ill., USA) according to the manufacturer's instructions. Cell debris was pelletted by centrifugation for $10 \mathrm{~min}$ at $12,000 \mathrm{~g}$ at $4^{\circ} \mathrm{C}$. The protein concentration in the supernatant was determined using a Pierce protein assay kit (Pierce Biotechnology) according to the manufacturer's instructions.

Twelve micrograms of each sample was solubilized by SDS sample buffer, separated by SDS-PAGE, transferred to polyvinylidene difluoride membrane (Immobilon-P; Millipore Co., Bedford, Mass., USA), Western blotted with each antibody and determined with ECL. For the reprobing of GAPDH, the membranes were washed 3 times with wash buffer (Tris-buffered saline containing $0.1 \%$ Tween-20 and $0.5 \%$ skim milk) and Western blotted with anti-GAPDH antibody, as described above.

The membrane was exposed to X-ray film (Fuji RX-U; Fuji Film Co., Minamiashigara, Japan), processed and photographed.

\section{Construction and Transfection of siRNA}

Stealth RNAi against Egr-1 and Stealth RNAi-negative control were purchased from Invitrogen. The sequences of the siRNA were sense 5'-AAAGGAUCCGAACGGGUCAGAGAUC- ${ }^{\prime}$ ' and antisense 5'-GAUCUCUGACCCGUUCGGAUCCUUU-3'. The sequence for the Stealth RNAi-negative control has not been reported. HCAECs were transfected with $10 \mathrm{nM}$ siRNA using Lipofectamine RNAi MAX (Invitrogen) for $6 \mathrm{~h}$ according to the manufacturer's instructions, and they were treated as described above. The specific gene silencing was confirmed by real-time PCR and Western blotting.

MCP-1 Assay

HCAECs transfected with either control siRNA or Egr-1-specific siRNA were stimulated with the stimulants for $16 \mathrm{~h}$. The levels of MCP-1 in the culture supernatants were determined by using commercially available ELISA kits (BioSource, Camarillo, Calif., USA) according to the manufacturer's instructions.

Statistical Analysis

Results were expressed as the mean \pm standard error of the mean. When two groups were compared, unpaired t test was used. Multiple comparisons were performed by ANOVA-Williams test was used for post hoc comparisons. A probability value $<0.05$ was considered statistically significant.

\section{Results}

Upregulation of Egr-1 Gene in HCAEC by

P. gingivalis Antigen and IL-6

HCAECs constitutively expressed low levels of Egr-1 mRNA. Stimulation with bacterial antigens derived from both the $P$. gingivalis strains upregulated the expression of Egr-1 in a dose-dependent manner. However, the stimulatory effect of $P$. gingivalis 381 was more robust compared with $P$. gingivalis SU63, particularly at a concentration of $10 \mu \mathrm{g} / \mathrm{ml}$, which resulted in a 2 -fold increase (fig. 1a).

The stimulatory effect of IL-6 was more prominent than that of $P$. gingivalis antigens. Since HCAECs are known to be deficient in functional IL- 6 receptor, a 10fold amount of recombinant sIL-6R was used in combination with IL-6. The expression of Egr-1 exhibited an approximately 2-fold greater increase at $1 \mathrm{ng} / \mathrm{ml}$ of IL-6 compared with unstimulated control. At $10 \mathrm{ng} / \mathrm{ml}$, the expression exhibited a greater than 8 -fold increase. Stimulation with $10 \mathrm{ng} / \mathrm{ml}$ IL-6 or $100 \mathrm{ng} / \mathrm{ml}$ sIL-6R exhibited only a 3 -fold increase, suggesting that the combination of IL-6 and sIL-6R is synergistic rather than additive (fig. 1b).

\section{Upregulation of MCP-1 Gene in HCAEC by}

P. gingivalis Antigen and $I L-6$

There was a weak stimulatory effect and no difference between $P$. gingivalis 381 and SU63 at 1-hour stimulation. Although the stimulatory effect was significant, dose dependency was not observed (fig. 2a).

The stimulatory effect of the combination of IL- 6 and sIL-6R on MCP-1 expression was similar to that of Egr-1. The most prominent effect was observed at the highest combination doses, with a 7-fold increase compared with unstimulated control. Stimulation with $10 \mathrm{ng} / \mathrm{ml}$ IL- 6 or $100 \mathrm{ng} / \mathrm{ml}$ sIL-6R only exhibited a 2.5 -fold increase, again suggesting that the effect of combination of IL- 6 and sIL$6 \mathrm{R}$ is synergistic rather than additive (fig. $2 \mathrm{~b}$ ). 


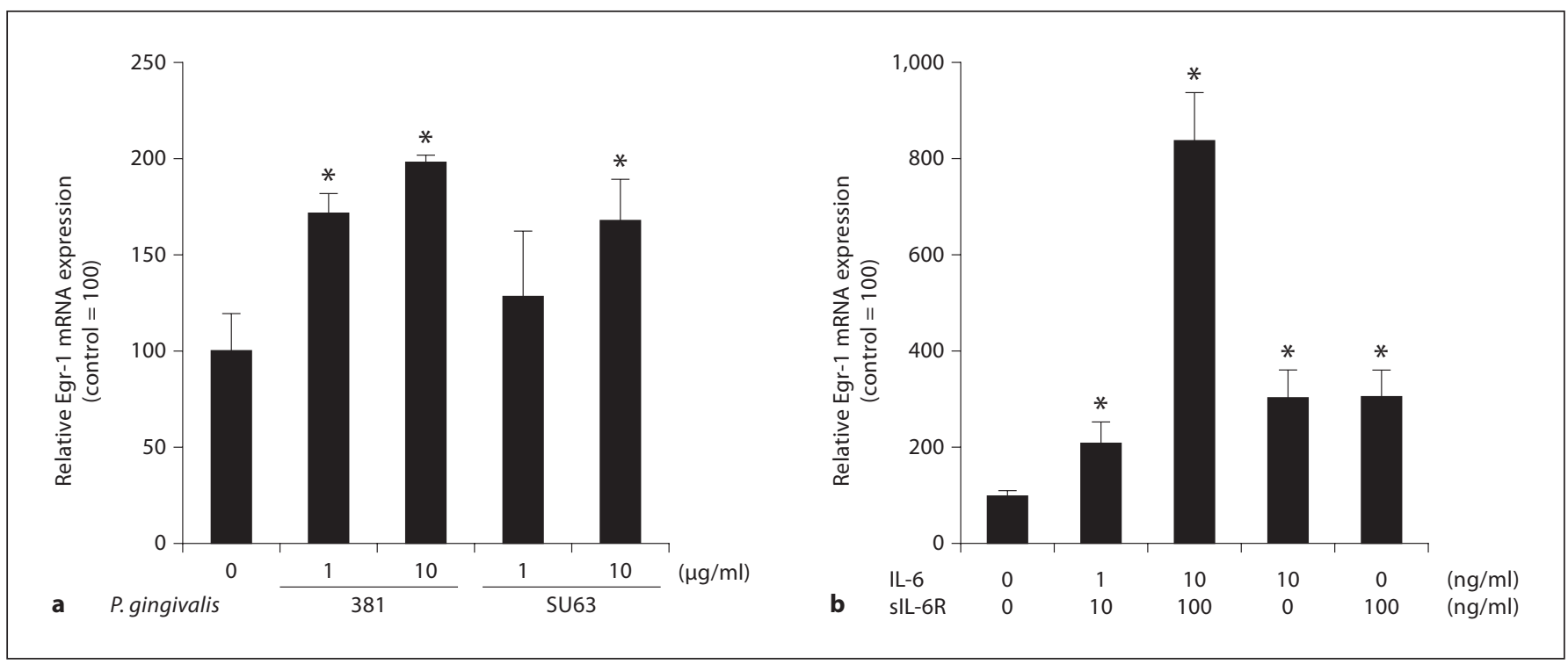

Fig. 1. Upregulation of Egr-1 in HCAECs by $P$. gingivalis antigens (a) and IL-6/sIL-6R (b). After stimulation for $1 \mathrm{~h}$, total RNA was extracted from the cells and Egr-1 gene expression was analyzed by real-time PCR. Data are expressed as mRNA expression rela- tive to the expression without stimulation. Results are shown as the mean \pm SE of 3 independent experiments. Difference in the effects of the different stimulants were analyzed by ANOVA-Williams test $\left({ }^{*} \mathrm{p}<0.05\right)$.

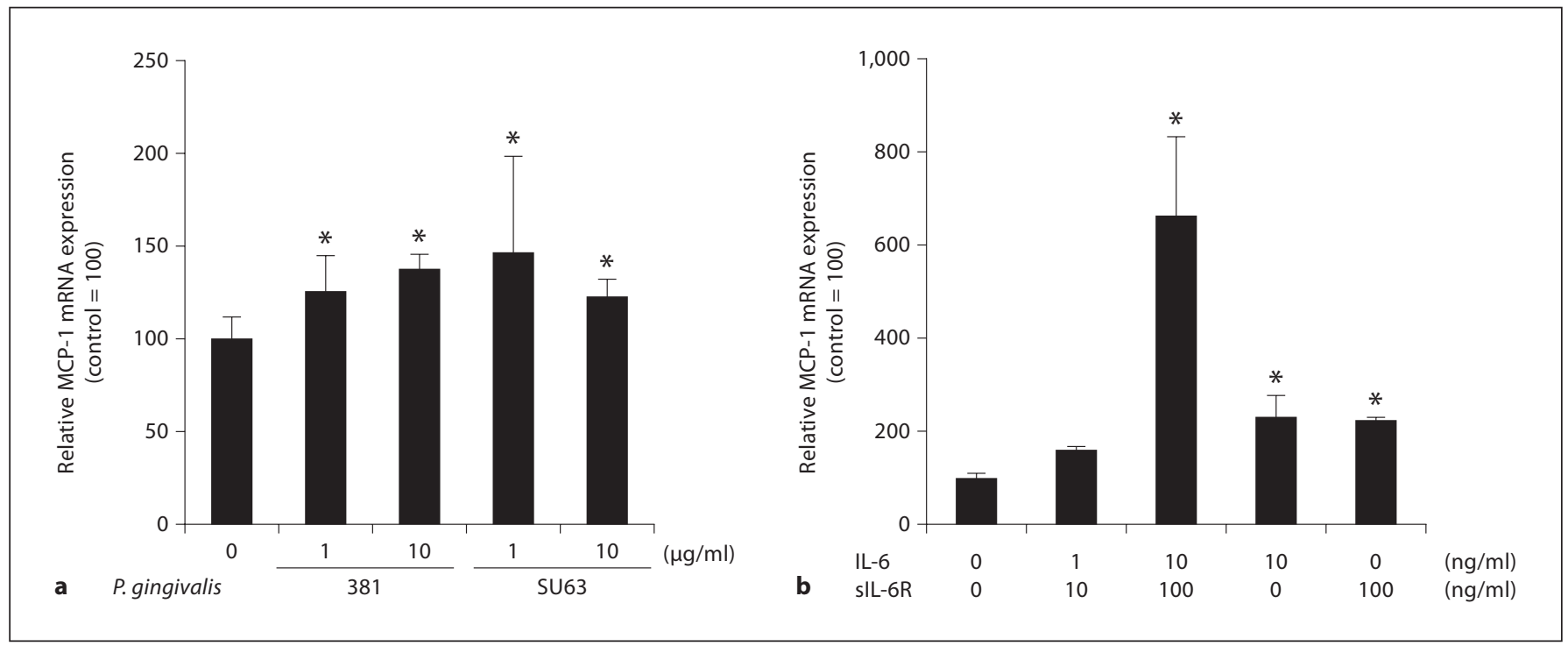

Fig. 2. Upregulation of MCP-1 in HCAECs by $P$ gingivalis antigens (a) and IL-6/sIL-6R (b). After stimulation for $1 \mathrm{~h}$, total RNA was extracted from the cells and MCP-1 gene expression was analyzed by real-time PCR. Data are expressed as mRNA expression relative to the expression without stimulation. Results are shown as the mean \pm SE of 3 independent experiments. Difference in the effects of the different stimulants were analyzed by ANOVAWilliams test $\left({ }^{*} \mathrm{p}<0.05\right)$. 


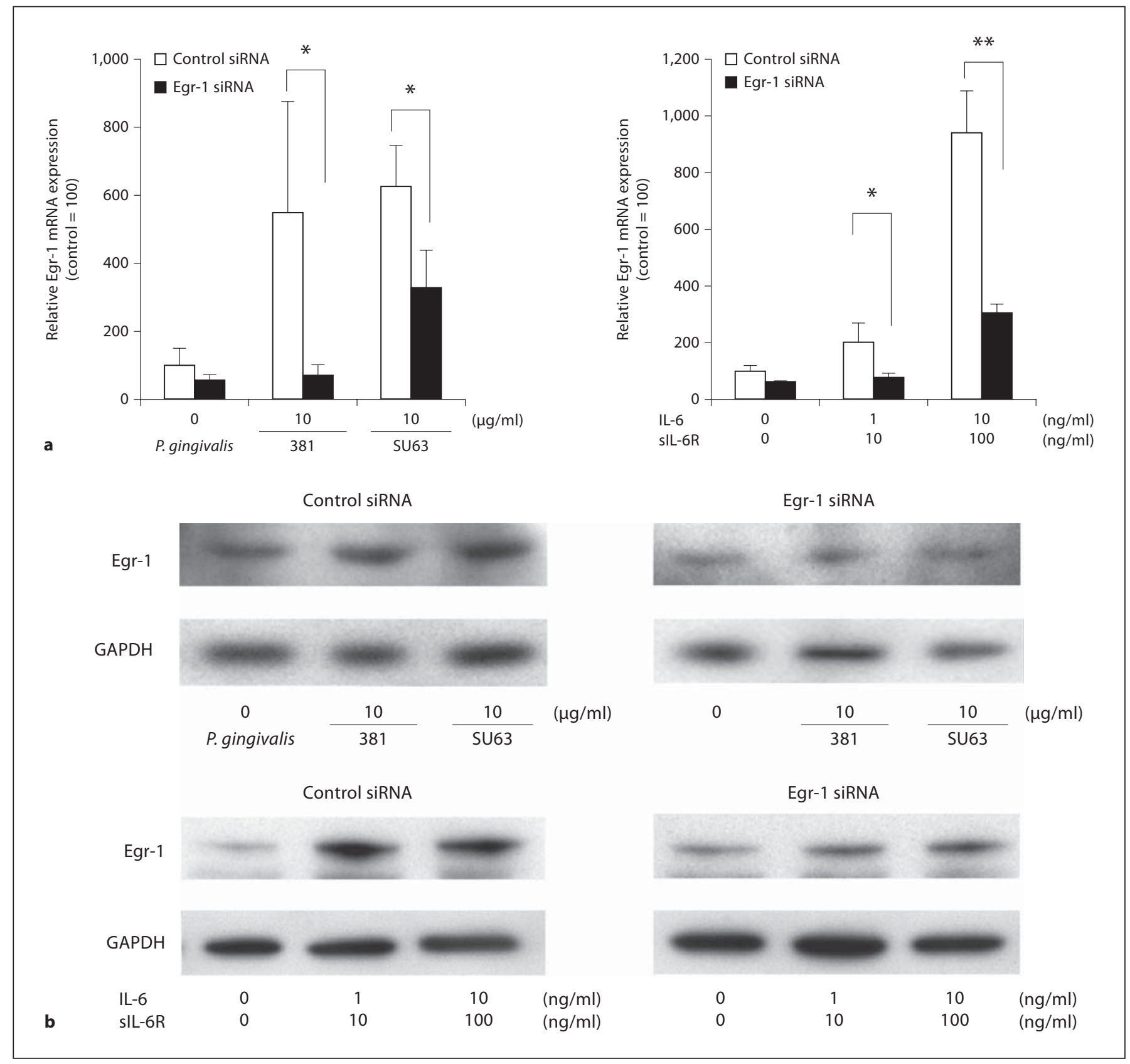

Fig. 3. Specific suppression of Egr-1 by siRNA transfection and the effect of suppression on stimulations. Negative control siRNA and Egr-1-specific siRNA were transfected into HCAECs at a concentration of $10 \mathrm{nM}$ and then stimulated with $P$. gingivalis anti- gens or IL-6/sIL-6R for $1 \mathrm{~h}$. The expression of Egr-1 was analyzed by real-time PCR (a) and Western blotting (b). $n=3$; mean \pm SE. Differences between the control siRNA and Egr-1 siRNA were analyzed by unpaired $t$ test $\left({ }^{*} \mathrm{p}<0.05 ;{ }^{* *} \mathrm{p}<0.01\right)$.
Specific Suppression of Egr-1 by siRNA and the Effect of This Suppression on MCP-1 Gene Expression Elicited by Stimulation

In order to confirm the specific suppression of Egr-1 by siRNA, specific siRNA and negative control siRNA were transfected into HCAECs at a concentration of 10 $\mathrm{nM}$, and expression of Egr-1 was measured at $6 \mathrm{~h}$. As shown in figure 3 , the stimulatory effect of IL-6/sIL-6R on Egr-1 expression was effectively downregulated by this treatment, with a $70 \%$ reduction at high doses of IL- 


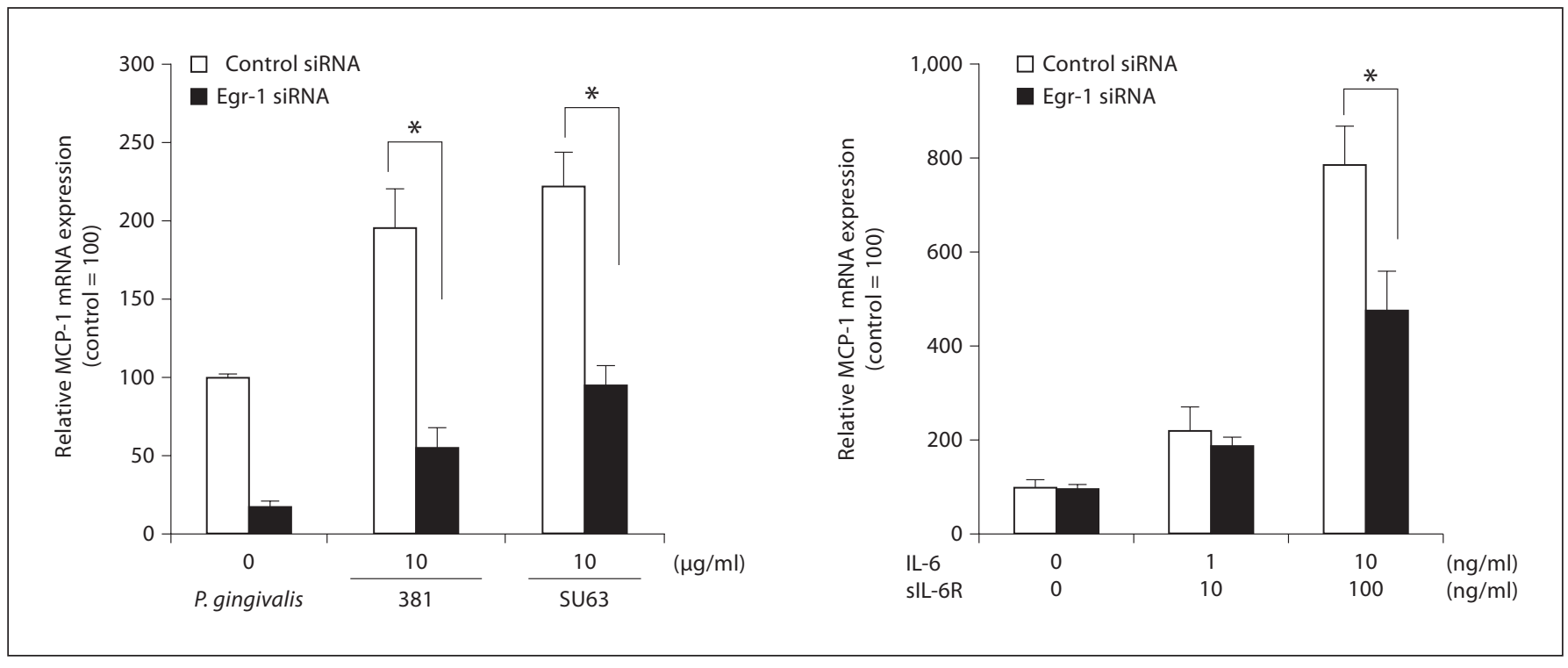

Fig. 4. Effects of specific suppression of Egr-1 by siRNA transfection on the gene expression of MCP-1. HCAEcs were transfected with negative control siRNA or Egr-1-specific siRNA, and then were either unstimulated or stimulated with the indicated stimulants for $1 \mathrm{~h}$. Total RNA was extracted from the cells and the ex- pression of MCP-1 mRNA was analyzed by real-time PCR. Results are shown as the mean \pm SE of 3 independent experiments. Differences between the control siRNA and Egr-1 siRNA were analyzed by unpaired $t$ test $\left({ }^{*} \mathrm{p}<0.05\right)$.
6/sIL-6R. Western blotting confirmed this effect of approximately $60-70 \%$ knock-down.

The effect of siRNA for Egr-1 was also evident in $P$. gingivalis-stimulated cultures. It is interesting that Egr-1 knock-down effect was different between strain 381 and SU63. Whereas the knock-down effect was $>80 \%$ for strain 381, an approximately $50 \%$ suppression was observed for SU63 stimulation. However, this difference was not obvious at the protein level (fig. 3b).

The effect of Egr-1 suppression on MCP-1 mRNA expression was determined (fig. 4). Egr-1-specific siRNA transfection showed that the mRNA for MCP-1 was downregulated in Egr-1-specific siRNA-transfected HCAECs stimulated with a combination of IL- 6 and sIL$6 \mathrm{R}$. This suggests that Egr-1 is involved in the MCP-1 expression in HCAECs stimulated with IL-6.

The effect of Egr-1 suppression on MCP-1 mRNA expression in $P$. gingivalis-stimulated culture was reflected by the difference in the Egr-1 knock-down effect with the different strains. MCP-1 gene expression was suppressed by $>70 \%$ in P. gingivalis 381-stimulated Egr-1knock-down HCAEC culture. However, $<60 \%$ suppression was observed in $P$. gingivalis SU63-stimulated culture.

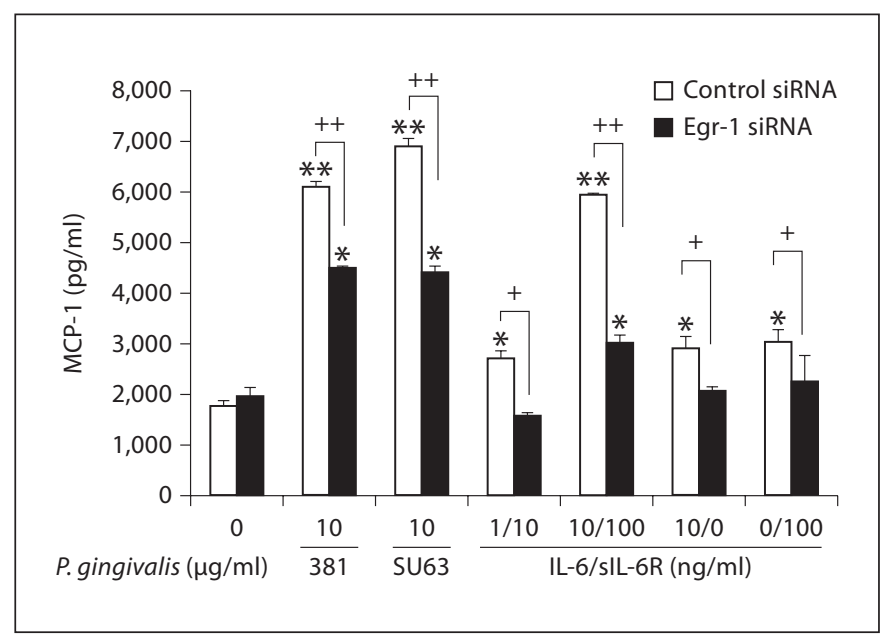

Fig. 5. Stimulatory effect of $P$. gingivalis antigens and IL-6/sIL-6R on MCP-1 production and effects of specific suppression of Egr-1 by siRNA transfection on the production of MCP-1. HCAEC cells were transfected with negative control siRNA or Egr-1-specific siRNA for $6 \mathrm{~h}$. Then the cells were either unstimulated or stimulated with the indicated stimulants for $16 \mathrm{~h}$. MCP-1 in the culture supernatant was analyzed by ELISA. Results are shown as the mean \pm SE of 3 independent experiments. Difference in the effects of the different stimulants were analyzed by ANOVA-Williams test $\left({ }^{*} \mathrm{p}<0.05 ;{ }^{* *} \mathrm{p}<0.01\right)$. Differences between the control siRNA and Egr-1 siRNA were analyzed by unpaired test $\left({ }^{+} \mathrm{p}<\right.$ $\left.0.05 ;{ }^{++} \mathrm{p}<0.01\right)$. 
Effect of Egr-1-Specific siRNA Transfection on MCP-1 Protein Production in Stimulated HCAECs

A substantial amount of MCP-1 was produced by HCAECs without stimulation. Although stimulation with a lower amount of IL-6/sIL-6R had a weak effect on the production, a significant increase in MCP-1 production was found in the culture stimulated with higher amount of IL-6/sIL-6R compared with a lower amount of IL-6/sIL-6R, as well as in unstimulated culture. The stimulatory effect of $P$. gingivalis antigen on MCP-1 production was more prominent compared with that of IL-6/ sIL-6R and the greater effect was observed in P. gingivalis SU63 stimulation.

Stimulatory effects of $P$. gingivalis antigens and IL-6/ sIL-6R on MCP-1 production were diminished by the transfection of Egr-1-specific siRNA into HCAECs. The suppressive effect of Egr-1 knock-down in IL-6/sIL-6Rstimulated culture was 50\%, whereas that in P. gingivalisstimulated culture was $30 \%$ for strain 381 and $40 \%$ for strain SU63 (fig. 5).

\section{Discussion}

Periodontal infection of endothelial cells has been implicated not only in the inflammation of periodontal tissues, but also as a link between periodontal disease and atherosclerotic cardiovascular disease. However, the cellular and molecular mechanisms by which periodontal infection participates in the development, progression and destabilization of atherosclerotic lesions remain to be elucidated. Several possible mechanisms include (1) direct effects of infectious agents on cellular components of the vessel wall, (2) increased expression of cytokines, chemokines and cellular adhesion molecules resulting in local endothelial dysfunction and (3) immune responses targeted to self-proteins located in the vessel wall mediated by molecular mimicry [14]. Egr-1, a major proatherogenic protein, has been shown to bind to promoters of cytokines, chemokines and proatherogenic factors, such as tissue factor and fibroblast growth factor 2 [15], as well as to regulate cell proliferation via DNA binding [16]. A number of studies have demonstrated that Egr-1 activation is involved in the development and progression of atherosclerotic lesions. Therefore, it is considered to be a key master regulator in multiple cardiovascular pathological processes [13]. Although the link between periodontal infection and Egr-1 activation in endothelial cells may be mediated by invasive bacterial components in the bloodstream and/ or pro-inflammatory cytokines, little is known on these mediating steps.

We have demonstrated that IL-6 levels in untreated periodontitis patients were significantly higher than those of healthy control subjects. After successful periodontal treatment, IL-6 levels significantly declined and approached control levels [11]. Furthermore, the serum IL-6 level has also been reported to be increased in experimental periodontitis in mice [17]. This led us to examine the effect of IL- 6 on the Egr-1 expression in endothelial cells. When the cells were stimulated with the combination of IL-6/sIL-6R, Egr-1 expression was significantly upregulated. However, C-reactive protein, another inflammatory marker linking periodontitis and cardiovascular disease, had little effect on the Egr-1 expression (data not shown). Whereas Egr-1 is reported to activate IL-6 transcription [18], this is first evidence to show IL- 6 stimulation increases Egr-1 activation, which may in turn potentiate atherogenic changes in endothelial cells. In support of this, Egr-1 expression was correlated with upregulation of MCP-1 expression. MCP-1, which is overexpressed in human and experimental atheroma, recruits the mononuclear phagocytes that characteristically accumulate in the nascent atheroma $[19,20]$. Our data is consistent with a previous report in which hypoxia induced Egr-1-dependent expression of MCP-1 mRNA [21]. Moreover, MCP-1 expression in aortic tissue is downregulated in the Egr-1 knock-out mouse compared with wild type [22].

Specific suppression of Egr-1 by siRNA effectively downregulated Egr-1 expression and resulted in reduced expression of MCP-1 in endothelial cells upon stimulation. This further supports the role of Egr-1 in MCP-1 regulation. In this regard, it is reported that inflammation-induced Egr-1 binds to the promoter region of the MCP-1 gene [18]. However, siRNA specific for Egr-1 downregulated the gene expression by $>60 \%$ (IL-6/sIL$6 \mathrm{R}$ ) and $>45 \%$ ( $P$. gingivalis), whereas the effect of Egr-1 suppression on MCP-1 production was less (approximately $40 \%)$. This suggests that the increased MCP-1 production induced by IL- 6 and $P$. gingivalis could also be mediated by the indirect activity of Egr-1-inducible genes, such as other cytokines or transcription factors. In this context, a number of genes downstream of Egr-1 activation have been reported. These include AP-2, RelA, Sp1 and NAB as transcription factors and TGF- $\beta$ and TNF- $\alpha$ as cytokines [23]. It is therefore quite likely that Egr-1 does not act alone, but works in concert with other transcription factors and cytokines [13]. 
The effect of $P$. gingivalis components on Egr-1 expression was weak compared with IL-6/sIL-6R stimulation, but still substantial, and no difference of stimulatory effect was observed between strains 381 and SU63. Only a few stimuli of vascular Egr-1 expression are known, such as VEGF, hypoxia and shear stress, and none are of microbial origin [24]. Recent observations have indicated that Egr-1 expression is sensitive to Chlamydia pneumonia infection. However, the observed effect cannot be regarded as specific for C. pneumonia. For example, Staphylococcus aureus or Escherichia coli infections of vascular cells may also promote Egr-1 up-regulation, although these acute infections result in cell death [25].

There are several similarities between C. pneumonia and P. gingivalis. Both of these bacteria invade endothelial cells and are associated with chronic and relatively mild inflammation [14]. In particular, $P$. gingivalis has a specific escape mechanism from host immune surveillance that is involved in a well-known phenomenon with chronic infection of this bacterium in periodontal tissue [26]. Chronic infection with $P$. gingivalis may induce relatively weak but nevertheless sustained activation of Egr1 in endothelial cells, leading to the subsequent vascular pathology. Consistent with this idea, $P$. gingivalis infection significantly increased human aortic endothelial cell production of IL-6, IL-8 and MCP-1 [27].

There are, however, also questions that still need to be answered. First, we used soluble antigens of $P$. gingivalis instead of whole bacteria as a stimulant. The concentration of $P$. gingivalis antigens used $(10 \mu \mathrm{g} / \mathrm{ml})$ corresponds to a multiplicity of infection of 1:50. Although $P$. gingivalis reportedly can invade endothelial cells in vitro and is found in atheromatous plaque $[28,29]$ with the frequen- cies of approximately $20 \%$ [30], there are also several reports of the presence of periodontal bacteria not being confirmed in atheromatous plaques [31, 32]. Furthermore, alteration of the gene expression profile of the aorta by oral infection with $P$. gingivalis accompanied by a failure of detection of the bacteria in the peripheral blood in mouse experimental periodontitis suggests that at least certain bacterial components may be involved in this response [Maekawa et al., in preparation]. Second, the concentrations of IL- 6 used in this study were higher than those seen in patients with chronic diseases. A number of studies have reported an elevated serum concentration of IL- 6 in patients with both periodontitis $[11,33,34]$ and CHD $[35,36]$ compared with nondiseased subjects, and the concentrations were on the picogram per milliliter order. On the other hand, most studies which have examined the effect of the biological activity of IL- 6 on various cells, including endothelial cells, have been on the nanogram per milliliter order $[37,38]$. Therefore, future studies will need to take these points into close account.

Nevertheless, accumulating evidence does suggest a biological basis for the link between periodontitis and cardiovascular disease. This study provides insight into the mechanisms by which periodontal infection may be involved in the atherosclerotic changes observed in patients with chronic periodontal infections.

\section{Acknowledgements}

This work was supported by grants from the Ministry of Education, Science, Sports and Culture of Japan (19390536, 19592384, 19791610, 20592426) and the Promotion of Niigata University Research Project.

\section{References}

Egr-1 Induced by $P$. gingivalis and IL-6 Regulates MCP-1 in Endothelial Cells
Ross R: Atherosclerosis - an inflammatory disease. N Engl J Med 1999;340:115-126.

2 Shah PK: Plaque disruption and thrombosis. Potential role of inflammation and infection. Cardiol Clin 1999;17:271-281.

3 Kuvin JT, Kimmelstiel CD: Infectious causes of atherosclerosis. Am Heart J 1999;137:216226.

4 Libby P, Egan D, Skarlatos S: Roles of infectious agents in atherosclerosis and restenosis: an assessment of the evidence and need for future research. Circulation 1997;96: 4095-4103.

5 Bahekar AA, Singh S, Saha S, Molnar J, Arora $\mathrm{R}$ : The prevalence and incidence of coronary heart disease is significantly increased in periodontitis: a meta-analysis. Am Heart J 2007;154:830-837.
Schenkein HA, Barbour SE, Berry CR, Kipps B, Tew JG: Invasion of human vascular endothelial cells by Actinobacillus actinomycetemcomitans via the receptor for plateletactivating factor. Infect Immun 2000;68: 5416-5419.

7 Spahr A, Klein E, Khuseyinova N, Boeckh C, Muche R, Kunze M, Rothenbacher D, Pezeshki G, Hoffmeister A, Koenig W: Periodontal infections and coronary heart disease: role of periodontal bacteria and importance of total pathogen burden in the coronary event and periodontal disease (corodont) study. Arch Intern Med 2006;166: 554-559. 
-8 Kuramitsu HK, Kang IC, Qi M: Interactions of porphyromonas gingivalis with host cells: implications for cardiovascular diseases. J Periodontol 2003;74:85-89.

$\checkmark 9$ Yamazaki K, Honda T, Domon H, Okui T, Kajita K, Amanuma R, Kudoh C, Takashiba S, Kokeguchi S, Nishimura F, Kodama M, Aizawa Y, Oda H: Relationship of periodontal infection to serum antibody levels to periodontopathic bacteria and inflammatory markers in periodontitis patients with coronary heart disease. Clin Exp Immunol 2007; 149:445-452.

-10 Ioannidou E, Malekzadeh T, Dongari-Bagtzoglou A: Effect of periodontal treatment on serum c-reactive protein levels: a systematic review and meta-analysis. J Periodontol 2006;77:1635-1642.

11 Nakajima T, Honda T, Domon H, Okui T, Kajita K, Ito H, Takahashi N, Maekawa T, Tabeta K, Yamazaki K: Periodontitis associated up-regulation of systemic inflammatory mediator level may increase the risk of coronary heart disease. J Periodont Res 2009, E-pub ahead of print.

12 Blaschke F, Bruemmer D, Law RE: Egr-1 is a major vascular pathogenic transcription factor in atherosclerosis and restenosis. Rev Endocr Metab Disord 2004;5:249-254.

13 Khachigian LM: Early growth response-1 in cardiovascular pathobiology. Circ Res 2006; 98:186-191.

14 Epstein SE, Zhou YF, Zhu J: Infection and atherosclerosis: Emerging mechanistic paradigms. Circulation 1999;100:e20-e28.

- 15 Fahmy RG, Dass CR, Sun LQ, Chesterman $\mathrm{CN}$, Khachigian LM: Transcription factor Egr-1 supports FGF-dependent angiogenesis during neovascularization and tumor growth. Nat Med 2003;9:1026-1032.

16 Fahmy RG, Khachigian LM: Locked nucleic acid modified DNA enzymes targeting early growth response-1 inhibit human vascular smooth muscle cell growth. Nucleic Acids Res 2004;32:2281-2285.

-17 Lalla E, Lamster IB, Hofmann MA, Bucciarelli L, Jerud AP, Tucker S, Lu Y, Papapanou PN, Schmidt AM: Oral infection with a periodontal pathogen accelerates early atherosclerosis in apolipoprotein e-null mice. Arterioscler Thromb Vasc Biol 2003;23:14051411.

-18 Hoffmann E, Ashouri J, Wolter S, Doerrie A, Dittrich-Breiholz O, Schneider H, Wagner EF, Troppmair J, Mackman N, Kracht M: Transcriptional regulation of EGR-1 by the interleukin-1-JNK-MKK7-c-Jun pathway. J Biol Chem 2008;283:12120-12128.
19 Boring L, Gosling J, Cleary M, Charo IF: Decreased lesion formation in CCR2-/- mice reveals a role for chemokines in the initiation of atherosclerosis. Nature 1998;394:894897.

20 Gu L, Okada Y, Clinton SK, Gerard C, Sukhova GK, Libby P, Rollins BJ: Absence of monocyte chemoattractant protein-1 reduces atherosclerosis in low density lipoprotein receptor-deficient mice. Mol Cell 1998;2: 275-281.

21 Yan SF, Fujita T, Lu J, Okada K, Shan Zou Y, Mackman N, Pinsky DJ, Stern DM: Egr-1, a master switch coordinating upregulation of divergent gene families underlying ischemic stress. Nat Med 2000;6:1355-1361.

22 Harja E, Bucciarelli LG, Lu Y, Stern DM, Zou YS, Schmidt AM, Yan SF: Early growth response-1 promotes atherogenesis: mice deficient in early growth response-1 and apolipoprotein E display decreased atherosclerosis and vascular inflammation. Circ Res 2004;94:333-339.

23 McCaffrey TA, Fu C, Du B, Eksinar S, Kent KC, Bush H, Jr., Kreiger K, Rosengart T, Cybulsky MI, Silverman ES, Collins T: Highlevel expression of Egr-1 and Egr-1-inducible genes in mouse and human atherosclerosis. J Clin Invest 2000;105:653-662.

24 Morawietz H, Ma YH, Vives F, Wilson E, Sukhatme VP, Holtz J, Ives HE: Rapid induction and translocation of Egr-1 in response to mechanical strain in vascular smooth muscle cells. Circ Res 1999;84:678-687.

25 Rupp J, Hellwig-Burgel T, Wobbe V, Seitzer $\mathrm{U}$, Brandt E, Maass M: Chlamydia pneumoniae infection promotes a proliferative phenotype in the vasculature through Egr-1 activation in vitro and in vivo. Proc Natl Acad Sci USA 2005;102:3447-3452.

26 Domon H, Honda T, Oda T, Yoshie H, Yamazaki K: Early and preferential induction of IL-1 receptor-associated kinase-M in THP-1 cells by LPS derived from porphyromonas gingivalis. J Leukoc Biol 2008;83: 672-679.

27 Roth GA, Moser B, Roth-Walter F, Giacona MB, Harja E, Papapanou PN, Schmidt AM, Lalla E: Infection with a periodontal pathogen increases mononuclear cell adhesion to human aortic endothelial cells. Atherosclerosis 2007; 190:271-281.

28 Padilla C, Lobos O, Hubert E, González C, Matus S, Pereira M, Hasbun S, Descouvieres $\mathrm{C}$ : Periodontal pathogens in atheromatous plaques isolated from patients with chronic periodontitis. J Periodontal Res 2006;41: 350-353.

-29 Zaremba M, Górska R, Suwalski P, Kowalski $\mathrm{J}$ : Evaluation of the incidence of periodontitis-associated bacteria in the atherosclerotic plaque of coronary blood vessels. J Periodontol 2007;78:322-327.
30 Yamazaki K, Ohsawa Y, Itoh H, Ueki K, Tabeta K, Oda T, Nakajima T, Yoshie H, Saito S, Oguma F, Kodama M, Aizawa Y, Seymour GJ: T-cell clonality to Porphyromonas gingivalis and human heat shock protein $60 \mathrm{~s}$ in patients with atherosclerosis and periodontitis. Oral Microbiol Immunol 2004;19: 160-167.

-31 Cairo F, Gaeta C, Dorigo W, Oggioni MR, Pratesi C, Pini Prato GP, Pozzi G: Periodontal pathogens in atheromatous plaques. A controlled clinical and laboratory trial. J Periodontal Res 2004;39:442-446.

32 Aimetti M, Romano F, Nessi F: Microbiologic analysis of periodontal pockets and carotid atheromatous plaques in advanced chronic periodontitis patients. J Periodontol 2007; 78:1718-1723.

33 D'Aiuto F, Parkar M, Andreou G, Suvan J, Brett PM, Ready D, Tonetti MS: Periodontitis and systemic inflammation: control of the local infection is associated with a reduction in serum inflammatory markers. J Dent Res 2004;83:156-160.

34 Pussinen PJ, Tuomisto K, Jousilahti P, Havulinna AS, Sundvall J, Salomaa V: Endotoxemia, immune response to periodontal pathogens, and systemic inflammation associate with incident cardiovascular disease events. Arterioscler Thromb Vasc Biol 2007; 27:1433-1439.

35 Ridker PM, Rifai N, Stampfer MJ, Hennekens $\mathrm{CH}$ : Plasma concentration of interleukin- 6 and the risk of future myocardial infarction among apparently healthy men. Circulation 2000;101:1767-1772.

36 Ridker PM, Hennekens CH, Buring JE, Rifai $\mathrm{N}$ : C-reactive protein and other markers of inflammation in the prediction of cardiovascular disease in women. N Engl J Med 2000; 342:836-843.

37 Romano M, Sironi M, Toniatti C, Polentarutti N, Fruscella P, Ghezzi P, Faggioni R, Luini W, van Hinsbergh V, Sozzani S, Bussolino F, Poli V, Ciliberto G, Mantovani A: Role of IL- 6 and its soluble receptor in induction of chemokines and leukocyte recruitment. Immunity 1997;6:315-325.

-38 Rott D, Zhu J, Zhou YF, Burnett MS, ZallesGanley A, Epstein SE: IL-6 is produced by splenocytes derived from CMV-infected mice in response to CMV antigens, and induces MCP-1 production by endothelial cells: a new mechanistic paradigm for infection-induced atherogenesis. Atherosclerosis 2003;170:223-228. 